\title{
Should I Stay or Should I Go? Perceived Barriers to Pursuing a University Education for Persons in Rural Areas
}

Laura Friesen \& R. J. Purc-Stephenson

University of Alberta

\begin{abstract}
A university education can provide an individual with greater employment options, higher income potential, and improved health and quality of life, yet young persons from rural areas remain less likely to attend university than their urban counterparts. This study explores the perceived personal, social, and cultural factors that might create barriers for young persons from rural areas. Semi-structured interviews were conducted with 17 individuals living in rural areas in Alberta, aged 18 to 23 years, who had not attended university. Using interpretative phenomenological analysis, we identified 11 major themes, which were then organized into a conceptual model to illustrate the interacting nature of these factors and their influence on a person's decision to pursue a university education. An examination of this model and its associated themes may help reveal the possible barriers young persons from rural areas experience when deciding whether or not to attend university.
\end{abstract}

\section{Résumé}

Uneformation universitaire peut permettreaux individus d'avoir un plus grand nombre d'options d'emploi et de meilleurs salaires, en plus d'améliorer leur santé et leur qualité de vie. Malheureusement, les jeunes des milieux ruraux demeurent moins enclins à fréquenter l'université que leurs homologues citadins. Cette étude se penche sur les facteurs personnels et socioculturels perçus qui pourraient ériger des barrières limitant l'accès universitaire aux jeunes adultes des milieux ruraux. Une étude basée sur des entrevues semistructurées a été réalisée auprès de 17 individus âgés de 18 à 23 ans habitant 
en milieu rural albertain et n'ayant pas fréquenté l'université. Avec l'analyse interprétative de phénomène, nous avons répertorié 11 thèmes majeurs, que nous avons regroupés en un modèle conceptuel afin d'illustrer la nature des interactions entre ces facteurs et leur influence sur la décision des personnes d'entamer des études universitaires. L'examen du modèle et des thèmes associés pourrait révéler les barrières possibles auxquelles font face les jeunes adultes issus de milieux ruraux lorsque vient le temps de choisir d'étudier ou non à l'université.

Attaining a university degree helps an individual achieve greater employment options, a higher income potential, and improved health and overall quality of life (Alberta Advanced Education [AAE], 2005). However, university enrolment is not evenly distributed across the population. According to the Youth in Transition Survey (Finnie, Childs, \& Wismer, 2011), those most likely to enrol in university tend to come from families with higher incomes and higher levels of parental education. Particularly noteworthy is that young persons from rural areas in Canada are less likely to attend university compared to their urban counterparts, $32 \%$ versus $45 \%$, respectively (Finnie et al., 2011). Although a growing body of research highlights how young persons from rural areas are underrepresented in universities across Canada (AAE, 2005; Arnold, Newman, Gaddy, \& Dean, 2005; Kirby, 2009), there remains little understanding as to what variables account for this "rural effect," over and above income and parental education.

Research exploring barriers to university for persons from rural areas traditionally has focused on broad demographic variables, such as socioeconomic status, cost, and geographical distance (Finnie et al., 2011; Frenette, 2006; Quinn, 2004). However, some research suggests that the barriers preventing rural youth from pursuing a university education are multidimensional and interrelated (AAE, 2005). For example, Engle and Tinto (2008) used data from the U.S. Department of Education and found that low-income, first-generation students face academic, social, and cultural adaptation barriers such as being older, having more obligations outside of school, and not receiving financial support from parents. Moreover, there are growing concerns about the cost of postsecondary education and the large debt loads that students develop (Finnie et al., 2011; Looker \& Lowe, 2001). The last is especially burdensome for rural students, who may need to move away from their community and, as a result, accumulate about $\$ 20,000$ or more of debt than those living at home during their education (Kirby, 2009).

Beyond cost, several social-related factors may represent barriers. For example, an Australian study by Alloway and Gilbert (2004) investigated differences in male and female enrolment trends and found that participants from rural areas held stronger expectations regarding male and female roles. For example, many believed "real" men work instead of study, and that university was boring and "for nerds." Moreover, male participants wanted to make money right after high school rather than studying for several years and having to rely on their parents to support them financially. Furthermore, because individuals from rural communities tend to have limited personal experience with university, students and parents generally rely on information provided by school counsellors or teachers (Lynch \& O'Riordan, 1998). However, rural schools tend to offer few, if any, 
postsecondary preparation courses (Alberta Students Executive Council, 2011; Arnold et al., 2005; Caledon Institute of Social Policy, 2010; Myers \& de Broucker, 2006). Indeed, results from a Canadian study found that rural students had lower levels of awareness of postsecondary school opportunities than urban students (AAE, 2005).

The limited exposure rural students have to information about university may make them uncomfortable with the idea of attending one. In fact, research shows that they worry about "fitting in" among their urban peers (Lehmann, 2007). The concern of "fitting in" supports Bourdieu's (1977) theory of habitus. Habitus refers to unconsciously learned norms and preferences, established through family upbringing, that guide how a person thinks, feels, and acts. That is, habitus is the lens through which individuals come to understand their world, where they fit in it, and what opportunities are within their reach, given their particular position in a society (Edgerton \& Roberts, 2014). Thus, persons from rural communities who have limited personal experience and little secondaryschool preparation for university may not pursue university because they may think it is an unreasonable goal for people like them.

A less studied area is how attending university may result in losing or diluting one's cultural identity. Because academia is based largely on individualistic and competitive values (Bagilhole \& Goode, 2001; Davalos, Chavez, \& Guardiola, 1999), it may be difficult for students from other cultures to negotiate the mismatch between the university's values and their own. For example, Fogel-Chance (1993) examined North Slope Inupiaq women in Alaska and found they struggled to maintain their identity as they entered the modern world to pursue university. In this qualitative study, parents noted how their children had changed when they returned home, and the parents feared they were forgetting their heritage and cultural traditions. As values are fundamental to a person's core identity (Shockley-Zalabek, 1988), it is possible that rural youths forgo pursuing university if they perceive a disparity between their values and a university's. Research examining students from other cultures suggests that greater perceived cultural incongruity is associated with more stress, depressive symptoms, and feelings of alienation and isolation (Cole \& Espinoza, 2008; Gonzalez, Stein, \& Huq, 2013). On the other hand, university may serve as a way of severing one's connections with a socially disadvantaged background (Johansson \& Hojer, 2012).

Understanding the potential barriers preventing rural youths from enrolling in university has never been more important, given the global aging crisis and the declining population in postsecondary schools (Finnie et al., 2011). There is a growing demand for highly skilled workers in Canada, and two-thirds of job openings over the next 10 years are expected to require postsecondary schooling (Kirby, 2009). Moreover, Alston (2004) examined the outmigration of youth from rural areas and argued that for rural areas to survive, they need to focus on human capital, institutional capital, and social capital. That is, rural communities need their youths to be educated to ensure the regeneration-and therefore survival-of the area.

To further understand why individuals from rural areas do not pursue a university education, the purpose of this study is to (1) explore the perceived personal, social, and cultural factors that might create barriers for them and (2) develop a conceptual model that illustrates the interacting nature of these factors and their influence on a person's decision to pursue a university education. 


\section{Methods}

\section{Research Design}

We used an interpretative phenomenological analysis (IPA) framework to explore how participants made sense of their personal and social reality (Larkin, Watts, \& Clifton, 2006). Beyond having participants describe their perceptions and experiences, IPA involves an interpretive component whereby the researcher attempts to get an "insider's perspective" so as to understand the participants' viewpoints. However, accessing this requires the active role of the researcher and his or her own perspectives to help to make sense of each participant's viewpoints (Larkin et al., 2006). In this study, the principle investigator (PI) came from a rural area in northern Alberta, and her perspectives were used during the interpretation activity. Thus, a two-stage interpretation process was involved, whereby the participant was trying to make sense of his/her world and then the researcher was trying to make sense of what the participant described.

\section{Setting}

For this study, we focused on people from rural Alberta. "Rural" is defined as towns, villages, and the surrounding areas; a town is at least 1,000 people but not greater than 10,000 , and a village has a population of at least 300 people (Government of Alberta, 2012). Alberta was selected not only to compare the experiences of people from similar cultural backgrounds but also because of its low postsecondary participation rates. Whereas approximately $17 \%$ of Albertans live in rural areas-which is similar to the national average of $19 \%$ (Statistics Canada, 2011)-only $71 \%$ of Albertans enrol in postsecondary school, which is below the national average of $79 \%$ and the lowest among the provinces (Statistics Canada, 2008). In terms of university, Alberta has the lowest enrolment compared to other provinces, with $34 \%$ of students enrolling in university and $62 \%$ in college or another type of postsecondary education (Statistics Canada, 2008).

Of the six public universities in Alberta, all but one (Athabasca University) are located in cities. While participants from the central or south-central regions are approximately two to three hours away from a university, participants located in the northern region are approximately six to seven hours from the nearest university (Athabasca University). However, Athabasca University is an online institution, and for those preferring an oncampus experience, the next closest universities are in Edmonton-approximately seven to eight hours away.

\section{Sample}

To be included in this study, participants needed (a) to be 18 years or older, (b) to be from a rural area in Alberta, and (c) never to have been enrolled in a university program. The age range was chosen to reflect individuals who were completing or had completed high school and those contemplating university. Participants included 17 individuals (12 female, five males), aged 18 to 23 years $(M=20.35$ years, $S D=1.21)$. Most lived in northwest Alberta $(n=11)$, while the remaining lived in central Alberta $(n=3)$ or south-central $(n=3)$ Alberta. The average population of the towns or villages participants came from was 2,494 , and the average driving distance to the closest city was approximately 3.74 
hours, ranging from about 30 minutes to six hours. Of the participants, one had completed trade school, two had started an online course at a college but had not completed it, and three were in their last year of high school; the remaining had a high-school diploma.

\section{Materials}

We developed an interview protocol based on the literature, and this guided each interview. There were three demographic questions that collected information on the participants' age, gender, and rural location, and 10 open-ended questions to capture participants' perceptions and/or experiences of university. Specifically, we asked about: the participants' career goals; the education expectations of their family and their community; perceived barriers to attending university; how attending university might affect their sense of self, their family, or their social life; perceived differences from their urban counterparts; and whether secondary school prepared them for university.

\section{Procedure}

Using convenience sampling, participants were recruited via notices posted in three recreation centres in Mackenzie Country in northwest Alberta, as well as 10 advertisements on free classified ad websites, including nine on Kijiji to target persons in central and southern communities and one on LaCreteOnline.com to target persons from northern communities. Individuals interested in participating contacted the PI by email or telephone, and those meeting the inclusion criteria were invited to participate in an individual, semi-structured telephone interview. Before beginning each interview, the researcher reviewed the informed consent form with the participant and explained that the responses would remain confidential and anonymous. Once informed consent was obtained, the interview began. Interviews took approximately one hour to complete. All interview data were audio-taped and transcribed verbatim. Participants were compensated $\$ 25$ for their time. The Research Ethics Boards at the University of Alberta approved this research.

\section{Data Analysis}

The transcribed data were analyzed to identify common themes for insights into the participants' experience and perspectives (Auerbach \& Silverstein, 2003), and proceeded in closely linked stages, including: (a) becoming familiar with the data by reading and rereading each transcript; (b) highlighting recurring patterns of meaning (ideas, thoughts, feelings); (c) developing a topic index; (d) using an index to code the data; (e) combining related topics to develop themes; and (f) creating superordinate themes by collapsing or refining themes. NVivo 10 software was used to manage the data, and the researchers met regularly to discuss the data. Any coding discrepancies were discussed and resolved through consensus.

\section{Results}

Of the 17 participants, five (29\%) were considering pursuing university. However, seven (58\%) of the remaining 12 participants noted they had previously considered pursuing university. After we had reviewed and analyzed the responses, 11 themes emerged from 
the data; we subsequently organized these into four major themes: pragmatic factors, psychological factors, family/social factors, and socio-cultural factors.

\section{Pragmatic Factors}

The pragmatic factors involve the relative accessibility of a university education and represent one of the issues influencing the participants' decision to enrol. Two themes emerged from the analysis: barriers relating to distance and to cost.

Distance. Twelve participants (71\%) identified distance between their home and the nearest university as a barrier. For all participants, going to university would entail moving away from home, meaning they would be moving three to eight hours away from family, friends, and current jobs. Nine participants mentioned there were community colleges within commuting distance, but they did not offer courses or programs of interest. When discussing distance issues, participants interpreted their circumstance in relation to their urban peers who were seen as being in a position of privilege because they could live at home while attending university. Feeling that attending university would uproot them from their home and community was a concern for many, and some mentioned they feared having their family spread across the province or country. For example, one participant explained, "I think for some people the distance that you have to go, like, it's always away from home ... and that keeps some people from going" (female, 23 years). However, five participants thought distance was not an issue. As one stated, "It's good to go try new places. I don't see how that would hinder me if I would have gone to university" (female, 20 years). However, these participants lived within three hours of a university. Thus, a transition to university did not seem as permanent or drastic, as they were still within commuting distance to connect with family and friends when they wanted.

Cost. Most participants $(n=12,71 \%)$ stated that in addition to rising tuition costs, the costs of living away from home created a barrier to attending university. Moreover, the distance between home and university would likely necessitate purchasing a vehicle, since Alberta has limited transit options (e.g., trains, buses) to link rural communities to university cities. While financial aid may be available, several participants perceived no obtainable support. For example, one participant explained, "In this community, parents don't pay for their children's education" (female, 21 years). Likewise, two participants firmly believed there was government funding for trade school but not for university. For example, one participant stated, "Trades are funded ... like if you go for training in trades, Alberta Works pays for it ... whereas if you go to university, it's, I've estimated, around 10 grand per year" (male, 20 years).

Several participants, especially males, applied a cost-benefit analysis that involved weighing the short-term financial benefits and drawbacks of attending university in Alberta. On the one hand, they could earn an education, but it would take time, and they would likely garner debt; on the other hand, they could find a high-paying job and buy the things they wanted now. As one participant explained:

Well . . . in Alberta we have the oil fields. It's really hard to justify going to school for so many years and spending just ridiculous amounts of money when you could make twice as much money and be debt free in the same amount of time. (male, 20 years) 
The economic boom in the province seemed to pull individuals to other attractive life paths, and when participants compared the two possible scenarios (university versus working), they did not recognize or value the benefit of a university education. One participant highlighted the immediate gains of choosing to work by stating: "like, just deciding, do I want debt for the next how many years or schooling or do I want a new pickup now just cause I can go work now ... go do a labouring job somewhere now" (male, 21 years). Several older participants said it would be "risky" for them to attend university now because they had already worked their way up to a certain point in a job where they felt financially secure. For example, one participant explained:

I've worked in one place for a long time. If you were to stop and then go pursue your schooling ... you, there, there's a fear that,, to get back to where you are now ... may be a struggle after ... because ... you're trying something new. (male, 21 years)

In this sense, "cost" also entailed potential earnings lost if a person left work to pursue university. Moreover, pursuing university after working for years would entail a considerable lifestyle change-one that participants were uncomfortable and almost fearful about making.

\section{Psychological Factors}

The psychological factors involve deeply personal values and beliefs that directly affect the individual and play a key role in their decision about pursuing university. Two themes emerged from the analysis: fear of the unknown and maintaining a rural identity.

Fear of the unknown. Nearly half of the participants (47\%) were fearful of what attending university might entail, in a broad sense. One participant mentioned the difficulty of actually preparing for a university education and making the initial commitment to go: "I guess just ... putting your foot out there and just starting ... is quite difficult" (male, 23 years). Others were specifically intimidated by the size of the university or anxious about relocating to an unfamiliar city, as well as having to drive in a big city, and associated safety concerns. As noted by one participant, "We come from a very sheltered community, so I think there's always that fear of going to a different ... city setting" (female, 23 years). Moreover, some were worried about choosing the "right degree" because if they did not, they might find themselves "stuck," unable to change their course of action easily, and burdened with the cost. For example, one participant stated: "You have to be sure of that, and if you second guess yourself, that sucks 'cause you already paid, and then you're stuck in university" (male, 20 years).

Maintaining a rural identity. Most participants ( $n=15,88 \%)$ feared becoming a different person and/or having their lives change drastically as a result of attending university. There were some internal tensions, in that participants seemed excited by the idea of change but also feared how it might alter their values or sense of self. According to one participant:

I think it'd be scary ... let's say, I have the chance to go to university and make something of myself ... I think I'd be scared to be somebody different and to know things differently ... to have my life change from where it is now. (female, 19 years)

Others drew upon their interactions with university-educated persons whose experience 
had changed them into someone now unduly arrogant. For these participants, choosing not to attend university was a way to preserve one's "goodness." For example, one participant explained:

I've realized, when people that have gone to school, they feel as if they are better than everyone else, they're higher, higher than everybody, and yes, they do have schooling but, uh, they feel as if they are doctors but they are not, they've gone to a few, a few classes, and maybe I resent that a little bit. (male, 21 years)

Other participants emphasized how attending university might strip away their rural identity. Indeed, growing up in a rural area was viewed as exceedingly positive and as contributing to wholesome values; one participant explained:

I loved the rural experience ... I wouldn't give it up for going to a . . city any day. It's made people who they are today. And like I said, a lot of people are better because they go to a smaller town or things like that. It's . . . different personalities, they're not, they do things for other people instead of for themselves to get themselves ahead, and that's what I find is different ... I don't know if that's probably the schooling and the parenting, but it's something out there that just makes people better. (male, 22 years)

Participants not only valued the rural experience in shaping who they were today, but compared themselves to their urban counterparts by downgrading the fast-paced and eclectic city-living experience. As one participant described:

I find that rural towns, they all have their own identity, and cities kind of just, a collective, morphing consciousness of everything. All the cultures, backgrounds, ethnicities, and it's, there's a lot of change going on in the city, whereas towns, like, try to stay the same. (male, 20 years)

On the surface, this "us versus them" assessment seems to imply that urban and rural cultures would not blend and that city living would eventually limit a person's freedom and distinctiveness. However, these participants' position against attending university may have been more implicit and rooted in a fear of changing their self-concept. Indeed, not attending university was viewed as a means of protecting one's values. For example, there was a common belief that cities "pollute" both the environment and the people living in it. As one participant explained:

Well really, if you just don't grow up with the pollution of the city, like not just actual pollution, but all the crap that goes on there ... you grow up with more, more things, more things than just sitting in front of a TV or a, or a game station or something like that. Like, you actually grow up doing stuff, and learning valuable lessons and stuff ... instead of just sitting inside. (male, 20 years)

\section{Family and Social Factors}

Family and social factors refer to how an individual's relationships with family 
and friends can directly and/or indirectly impact the decision to attain a university education. Three themes emerged from the analysis: parental education, relationships, and responsibilities.

Parental education. Although most participants stated that their parents would support them regardless of what education route they took, approximately half believed their parents' level of education influenced their decision to pursue university. None of our participants' parents had attended university, and most expected to follow in their parents' footsteps in terms of educational attainment. In fact, some participants were uncomfortable at the thought of moving beyond their parents' education level. For example, one participant explained:

If my parents had gone to college, I guess it would have encouraged me a little bit more 'cause ... If your parents do something you feel ... feel more like you can do it ... sometimes, but them not having done it, I guess . . . I don't know, I guess I've never felt very pushed to go further than high school. (female, 23 years)

Conversely, other participants believed their parents' level of education served as motivation and as a yardstick for their expected educational attainment. Feeling like there are educational parameters within (but not beyond) which one can move may be a manifestation of Bourdieu's (1977) idea of habitus. For instance, one participant said:

I think if they had graduated out of a college it would have given me more motivation to go into a college ... you wouldn't have even had to discuss it. You would know that they've done it so . . . it would be something you . . . you should maybe do too. (male, 21 years)

Relationships. Nearly three quarters $(n=12,71 \%)$ stated that attending university would physically isolate them from their family and friends because of the distance to school and also because they would be spending their time studying. As one participant explained:

It would distance me from my family a great deal, 'cause school is pretty busy and I would probably attend full-time and my family would be, like, around eight hours away, so I wouldn't be with my family a whole lot and . . . it would affect my personal relationship with my family. (female, 21 years)

Indeed, many participants placed a higher value on maintaining existing relationships than on pursuing education, especially if the individual was in a romantic relationship. As one participant explained, "Well [the guidance counsellor] did ask me where I wanted to go if I wanted to pursue a career but I currently had a boyfriend so I told him no. So that's as far as it went" (female, 20 years). However, five participants agreed that attending university might result in losing existing friendships but also mentioned that they would likely meet more friends there. For example, one participant explained, "I'd assume I would make more friends in school so that, that would definitely be a positive thing. I would like meeting new people" (male, 21 years).

Responsibilities. For those participants who identified being married and/or having children of their own $(n=8)$, a responsibility to others was viewed as an impor- 
tant factor. Finances were seen to be a factor that could put stress on relationships. For example, one participant stated, "Well now I'm married so uh . . . I have to provide for my [family] 'cause my wife is taking care of our child ... I wouldn't know how to provide for them while going to school without a full-time job" (male, 21 years). Others described how they would have to distribute responsibilities and how their spouse would have to change his or her life should they decide to attend university. As one participant explained, "I would be gone most of the day and would have to get a daycare provider to take care of my child, and my husband would have to relocate jobs" (female, 21 years). Another participant, who was expecting her third baby, thought attending university would make her feel guilty: "I would just, you know, feel guilty .. . 'what's my family doing,' or, you know, 'how are they doing' ... um, I should be there and not here . . . you know. Kind of like that. [I'd] feel like I abandoned them" (female, 19 years).

\section{Socio-cultural Factors}

The third theme, socio-cultural factors, refers to societal-level variables in the participants' lives, such as social norms, traditions, and community values, which can indirectly influence their decision to pursue university.

Traditional values and beliefs. Eight participants mentioned that the traditional values held by their community made people think university was unnecessary or, in a few cases, a "bad thing." For example, several participants believed their community members feared children "learning too much," which would make them question and reject their values and beliefs. In fact, these participants perceived that labour-type work within the community was considered "real-world" work and was more highly valued than studying at a university. As one participant explained:

Some people think that it doesn't make a difference if you go to school, [they'd] rather have it if you just worked hard, then try something else . . . or they don't believe that you have to or that you even should. To some degree, reputation and respect in the community is your highest [priority] . . . is almost valued higher than, than level of education. (male, 21 years)

There was a general perception that their communities devalued a university education, perhaps because they did not recognize how it would immediately benefit the community. Some highlighted the tension surrounding this issue and their own internal struggle with deciding whether or not to go. That is, going to university would make them stand out among their peers but might also put them at odds with tradition. As one participant explained:

Depending on who you ask in my community ... um ... it can be a good thing. People can look up to you for attending a university, but some of my family is pretty against and rather have you stick to traditional, so-called guidelines. (female, 21 years)

Gender-role expectations. Most participants $(n=11,65 \%)$ seemed to agree that their community upheld strong gender-role expectations, and several participants mentioned that males would be encouraged more than single females to get a university ed-

ucation. For example, when discussing female roles in his community, one participant 
remarked about the beliefs of some community members: "[females] should be more in charge of the house and ... as they will be ... could be mothers soon and then ... and then all their schooling would be for nothing" (male, 21 years). Likewise, another participant commented on how people in her community perceived female roles: "Their personal preference for young women would be [for them] to get married at a young age and bear children and not to work" (female, 21 years). Having young persons venture off to university could put a community at risk in that there would be fewer people to work or to reproduce. Some participants perceived that many community members wanted young people to put their own goals aside and put the community's needs first. Those who deviated from this expectation, especially females, seemed to be viewed negatively.

Maintaining social norms. Most participants $(n=15,88 \%)$ felt pressured by their community to maintain traditional social norms. According to one participant, "like in [town], you're expected to be married at 18 and have kids by, by the time you're 20, like, and college is weird in [town] like, for most people" (female, 18 years). Dropping out of high school was mentioned by one participant as a norm in her community. Of those who did finish high school, several participants highlighted that their community tended to push the young people to go to trade school rather than university. Again, it appears a community can exert pressure on young persons to maintain the status quo, resist change, and look for immediate/short-term ways in which they can add value to their community.

Secondary-school preparation. About half (47\%) believed their high schools had done a good job at preparing students for university; the remaining identified a number of deficiencies, ranging from simple encouragement to having them apply to specific program options. For example, one participant stated, "I guess for me, I would have said the only encouragement that I got was to go ... not what for or where" (female, 23 years). Moreover, school-advice counsellors and teachers tended to focus on the negative aspects of university, such as the short-term hardships, instead of assessing a student's potential. Participants mentioned hearing few success stories about attending university, and the stories they did hear made them feel discouraged, intimidated, and ill prepared to even apply. As one participant explained:

He tried making it seem like such a big deal and it kinda made me think, like ... I'm not good enough ... and my other teachers were like, "Yeah, the workload in university is crazy," like they were always talking about ... how intense it is, and through all my teachers talking about their university experiences, saying how like, "Oh yea, I have had so much debt," or, "I didn't have any time to socialize 'cause I was always studying," or there were stories like, I don't know, just there weren't really any good stories from university from any of my teachers, other than what they learned, which is the benefit but ... but they like focused on the barriers, maybe a lot. (male, 20 years)

The lack of secondary-school guidance or motivation to attend university may be another example of Bourdieu's (1977) idea of habitus. Specifically, educators were actively discouraging young persons from the idea of pursuing university, by relaying stories of hardships, debts incurred, and strains on relationships-all of which acted to reaffirm the young persons' understanding that a university education is not a realistic goal for people in a rural area. 


\section{A Conceptual Model}

The five participants still considering university did not know when it might happen, wondered whether they would fit in, were concerned about the strain it might put on their family and friendships, and yet showed signs of enthusiasm at the prospect of doing something unexpected with their lives. Indeed, the decision to pursue university seems to be an ongoing process, during which a range of variables are considered and pitted against each other.

To illustrate the factors influencing a person's decision to pursue university, we organized the themes into a conceptual process model (Figure 1). Moving from left to right in the model, a person would likely think about the Accessibility Factors first, which include the admission requirements of the institution, pragmatic factors such as cost and distance to the institution, and their level of secondary-school preparation. Next, several Psychosocial Factors may influence their decision, which we have broken down into four reciprocal and interacting factors: identity issues (e.g., how university might change their sense of self), fear of the unknown (e.g., moving somewhere unfamiliar to do something uncharacteristic of others they know), parental education level (e.g., parental education could influence what educational goals are realistic, expected, or supported), and relationships and responsibilities at home (e.g., being physically isolated from family and friends, putting potential strains on existing relationships). However, all of these factors are embedded within the broader Socio-cultural Influences of the community from which the student comes, involving social norms, traditions, and gender-role expectations.

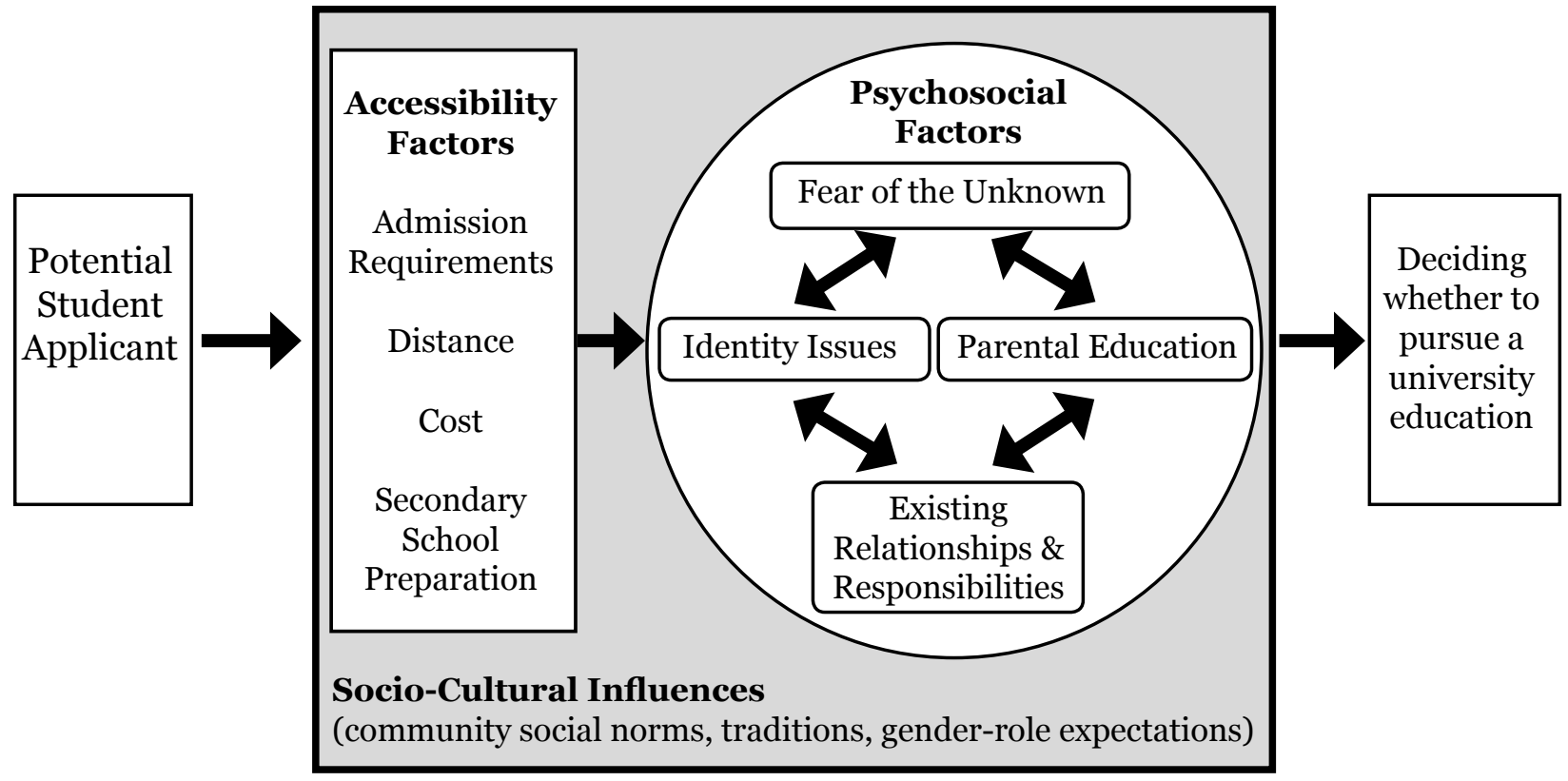

Figure 1. A conceptual model illustrating the factors influencing a person's decision to pursue university. 


\section{Discussion}

Consistent with previous research (e.g., Barr-Telford, Cartwright, Prasil, \& Shimmons, 2003; Bélanger, Akbari, \& Madgett, 2009; Irvin, Byun, Meece, Farmer, \& Hutchins, 2012), we found that young persons from rural areas face a number of obstacles, beyond finances and distance, that influence their decision to pursue university. To understand the dynamic relations among the various factors identified, we developed a conceptual model (Figure 1) that illustrates the decision-making process when a person from a rural area is considering university.

About a third of students interested in pursuing university have their educational dreams crushed due to cost (Bélanger et al., 2009; Frenette, 2009). Whereas several participants identified cost as a barrier, it was irrelevant for others because they had low educational expectations-university was something they never seriously considered. These results support the findings by Andres and Looker (2001), who found that rural youth in British Columbia and Nova Scotia had lower educational aspirations compared to those living in urban areas, even after the researchers had controlled for gender and parental education. Other studies (e.g., Irvin et al., 2012) have reported similar findings and suggested that rural youth prefer gaining full-time employment after high school instead of pursuing university.

A contributing factor to low educational aspirations may be that pursuing university would require relocating to do something unfamiliar. About half of our participants feared having to relocate to a city or being unable to determine the outcomes of a university degree (e.g., what job they would get), but most feared they would lose their "rural identity." Consistent with Childs and Melton's (1983) description, "rurality" involves a set of values and a lifestyle that seem in conflict with the values of competition and individualism characteristic of universities and urban living. Previous research by Fogel-Chance (1993) described how Alaskan women who pursued university created a dual identity-a school self and a home self-and often felt they lived in two competing worlds. As values underlie most social behaviour (Rokeach, 1973), rural youth may be uncomfortable negotiating the perceived mismatch in values and thus decide not to pursue university. Future research could explore how rural students negotiate their identity when making the transition to university and what impact this has on their university experience.

Educational aspirations also derive from a person's social reality (Bernstein, 1971; Bourdieu, 1977). For example, few rural youths saw people "like them" going to university and getting good jobs, which in turn influenced their own educational plans. According to a Canadian study of approximately 20,000 youths, higher-education plans of friends strongly influenced a student's own plans (Bélanger et al., 2009). As "fitting in" matters, university recruitment offices could consider having cultural congruity connections available on campus (e.g., clubs, groups) to attract and retain students from rural areas. Moreover, approximately half of the participants in our study were married or had a family to support, so pursuing a university education was not a realistic goal when they had others to support. Needing to help or support family was one of the most common barriers identified by nearly 30\% of rural youths in a large and diverse US study (Irvin et al., 2012). Future research could explore how rural youths can pursue university without compromising family relationships or responsibilities. 
One of the most important contributions of our study was describing how the culture of a community can influence an individual's educational goals. These results support previous research that being in a rural area can interact with social and cultural norms to constrict youths' educational plans (Farmer et al., 2006; Hardré \& Sullivan, 2008). Many participants viewed their community as having "traditional values," social norms, and gender-role expectations whereby young persons were encouraged to find employment, maybe earn a skilled trade, and get married, but ultimately stay in the community. Because a community can pressure youths to stay near family, moving away for school can be especially stressful. As a result, rural youths in this study may have lowered their educational aspirations and pursued local opportunities instead, which is also consistent with previous research (Ali \& Saunders, 2009; Hardré \& Sullivan, 2008).

However, lower university enrolment rates could be explained by the other opportunities available in the area. For example, attracting rural students, particularly males, to university in Alberta may be challenging in a time of economic boom when there is a high demand for low-skilled labour and industries are willing to pay large wages. For our participants, the perceived benefits of attaining a university education were outweighed by the immediate benefits of employment in the oil fields. In fact, rural areas in Alberta are heavily dependent on primary industries (e.g., agriculture, oil and gas extraction), with about $15 \%$ of residents working in primary industries compared to about $3 \%$ of people living in Calgary or Edmonton (AAE, 2005).

Infusing a community with highly educated workers benefits the individual, improves the standard of living in the area, and contributes to overall economic growth (Lehmann, 2007). Thus, encouraging young persons from rural areas to attend university may bring significant value to their communities and beyond. Consistent with previous research (Arnold et al., 2005), we found that school-advice counsellors and teachers seemed to do little to push students to pursue a university education, and schools appeared to offer little formal or informal information about university opportunities. University recruitment offices may need to connect with rural secondary schools to establish stronger links and thereby provide students with the support they need when deciding whether attending university is the right decision for them.

Identifying what factors play a role in a person's decision to pursue university is valuable, but combining those factors to create a conceptual model with practical implications is even better. Our model makes a valuable contribution to literature in this area and lends support to Bourdieu's (1977) theory of habitus. For example, if habitus guides how a person thinks, feels, and acts, this may explain why persons from rural areas do not pursue, or delay pursuing, a university education-they have been conditioned to believe university is not a reasonable goal for people "like them." However, habitus can evolve with new experiences. For example, rural youths with peers who have gone to university, or who receive more information about postsecondary school opportunities from teachers or counsellors, could result in a habitus shift.

Despite the strengths of this study, there are several limitations worth noting. First, we recruited individuals from rural Alberta to compare the experiences of people from similar cultural backgrounds. While this helped eliminate a heterogeneity in our sample, it limits the generalizability of our findings. Moreover, we used convenience sampling, and most of our participants were females. Despite recruitment efforts that targeted both genders, and persons from northern, central, and southern areas in Alberta, it is difficult 
to determine whether selection bias influenced the results. However, some research has found that gender does not predict perceived educational barriers among rural youth (Irvine et al., 2012). A larger study, using a stratified sampling strategy, should be conducted to validate our findings and test our model.

A number of factors seem to influence a person's decision to pursue university, over and above distance, cost, and parental education. The current study supports existing research that shows other significant barriers: self-expectations, parental expectations, and secondary school preparation. Moreover, we have extended this body of research by showing how identity issues and socio-cultural factors can also influence a person's decision. The factors identified in this study are represented in a model that needs to be tested using different populations. Thus, this model may be a starting point for future research to investigate the complex web of factors that play a role in a young person's decision to pursue university.

\section{References}

Alberta Advanced Education. (2005). Increasing accessibility to advanced education for under-represented Albertans. Retrieved from www.assembly.ab.ca/lao/library/ egovdocs/2005/alae/150151.pdf

Alberta Students Executive Council. (2011). Unleashing aurora: Increasing accessibility for Alberta's rural and northern students. Retrieved from http://static1. squarespace.com/static/50a44762e4bo13bo4b87badd/t/51a641b2e4boaod58d8 1e874/1369850290915/Unleashing+Aurora+-+ASEC.pdf

Ali, S. R., \& Saunders, J. L. (2009). The career aspirations of rural Appalachian high school students. Journal of Career Assessment, 17(2), 172-188.

Alloway, N., \& Gilbert, P. (2004). Shifting discourses about gender in higher education enrolments: Retrieving marginalised voices. International Journal of Qualitative Studies in Education, 17(1), 103-118.

Alston, M. (2004). "You don't want to be a check-out chick all your life": The outmigration of young people from Australia's small rural towns. Australian Journal of Social Issues, 39(3), 299-312.

Andres, L., \& Looker, E. D. (2001). Rurality and capital: Educational expectations and attainments of rural, urban/rural and metropolitan youth. Canadian Journal of Higher Education, 31, 1-45.

Arnold, M. L., Newman, J. H., Gaddy, B. B., \& Dean, C. B. (2005). A look at the condition of rural education research: Setting a direction for future research. Journal of Research in Rural Education, 20(6), 1-21.

Auerbach, C. F., \& Silverstein, L. B. (2003). Qualitative data: An introduction to coding and analysis. New York, NY: New York University Press.

Bagilhole, B., \& Goode, J. (2001). The contradiction of the myth of individual merit, and the reality of a patriarchal support system in academic careers: A feminist investigation. European Journal of Women's Studies, 8(2), 161-180.

Barnhardt, C. (1992). Life of the other side: Native student survival in a university world. Peabody Journal of Education, 69, 115-139. 
Barr-Telford, L., Cartwright, F., Prasil, S., \& Shimmons, K. (2003). Access, persistence and financing: First resultsfor the postsecondary education participation survey (PEPS). Ottawa, ON: Statistics Canada. Retrieved from http://publications.gc.ca/site/archiveearchived.html? url=http://publications.gc.ca/Collection/Statcan/81-595-MIE/81-595MIE2003007.pdf

Bélanger, C. H., Akbari, F., \& Madgett, P. J. (2009). Why some youths do not realise their post-secondary education aspirations. Tertiary Education and Management, 15(3), 209-225.

Bernstein, B. (1971). Class, codes, and control. London, UK: Routledge \& Kegan Paul.

Bourdieu, P. (1977). Outline of a theory of practice (vol. 16). New York, NY: Cambridge University Press.

Caledon Institute of Social Policy. (2010, March). Barriers to post-secondary education. Caledon Commentary. Retrieved from http://www.caledoninst.org/Publications/ PDF/861ENG.pdf

Cerezo, A., \& Chang, T. (2013). Latina/o achievement at predominantly White universities: The importance of culture and ethnic community. Journal of Hispanic Higher Education, 12(1), 72-85.

Childs, A. W., \& Melton, G. B. (Eds.). (1983). Rural psychology. New York, NY: Plenum.

Cole, D., \& Espinoza, A. (2008). Examining the academic success of Latino students in science technology engineering and mathematics (STEM) majors. Journal of College Student Development, 49(4), 285-300.

Davalos, D. B., Chavez, E. L., \& Guardiola, R. J. (1999). The effects of extracurricular activity, ethnic identification, and perception of school on student dropout rates. Hispanic Journal of Behavioral Sciences, 21(1), 61-77.

Edgerton, J. D., \& Roberts, L. W. (2014). Cultural capital or habitus? Bourdieu and beyond in the explanation of enduring educational inequality. Theory and Research in Education, 12(2), 193-220.

Engle, J., \& Tinto, V. (2008). Moving beyond access: College success for low-income, first-generation students. Pell Institute for the Study of Opportunity in Higher Education. Retrieved from http://eric.ed.gov/?id=ED504448

Farmer, T. W., Dadisman, K., Latendresse, S. J., Thompson, J., Irvin, M. J., \& Zhang, L. (2006). Educating out and giving back: Adults' conceptions of successful outcomes of African-American high school students from impoverished rural communities. Journal of Research in Rural Education, 21, 1-12.

Fedukovich, C. (2013). Standing against future contingency: Activist mentoring in composition studies. Workplace, 22, 40-52.

Finnie, R., Childs, S., \& Wismer, A. (2011). Access to post-secondary education among under-represented and minority groups: Measuring the gaps, assessing the causes. Education Policy Research Initiative. Working Paper No. 2011-01. Retrieved from http:// www.ruor.uottawa.ca/handle/10393/31424 
Fogel-Chance, N. (1993). Living in both worlds: "Modernity" and "tradition" among North Slope Inupiaq women in Anchorage. Arctic Anthropology, 30(1), 94-108.

Frenette, M. (2006). Too far to go on? Distance to school and university participation. Education Economics, 14, 31-58.

Frenette, M. (2009). Do universities benefit local youth? Evidence from the creation of new universities. Economics of Education Review, 28(3), 318-328.

Gonzalez, L. M., Stein, G. L., \& Huq, N. (2013). The influence of cultural identity and perceived barriers on college-going beliefs and aspirations of Latino youth in emerging immigrant communities. Hispanic Journal of Behavioral Sciences, 35(1), 103-120.

Government of Alberta. (2012). Types of municipalities in Alberta. Retrieved from http://www.municipalaffairs.alberta.ca/am_types_of_municipalities_in_alberta.cfm

Hardré, P. L., \& Sullivan, D. W. (2008). Student differences and environment perceptions: How they contribute to student motivation in rural high schools. Learning and Individual Differences, 18, 471-485.

Irvin, M. J., Byun, S. Y., Meece, J. L., Farmer, T. W., \& Hutchins, B. C. (2012). Educational barriers of rural youth: Relation of individual and contextual difference variables. Journal of Career Assessment, 20, 71-87.

Johansson, H., \&Höjer, I. (2012). Education for disadvantaged groups: Structural and individual challenges. Children and Youth Services Review, 34(6), 1135-1142.

Kirby, D. (2009). Widening access: Making the transition from mass to universal post-secondary education in Canada. Journal of Applied Research on Learning, 2, 1-16.

Laing, C., Chao, K., \& Robinson, A. (2005). Managing the expectations of non $\square$ traditional students: A process of negotiation. Journal of Further and Higher Education, 29, 169-179.

Larkin, M., Watts, S., \& Clifton, E. (2006) Giving voice and making sensein interpretative phenomenological analysis. Qualitative Research in Psychology, 3, 102-120.

Lehmann, W. (2007). "I just didn't feel like I fit in": The role of habitus in university dropout decisions. Canadian Journal of Higher Education, 37, 89-110.

Little, P. S., \& Miller, S. K. (2007). Hiring the best teachers? Rural values and personorganization fit theory. Journal of School Leadership, 17(2), 118-158.

Looker, D. E., \& Lowe, G. S. (2001). Post-secondary access and student financial aid in Canada: Current knowledge and research gaps. Canadian Policy Research Networks. Retrieved from http://cprn.org/documents/19327_en.pdf

Lynch, K., \& O'Riordan, C. (1998). Inequality in higher education: A study of class barriers. British Journal of Sociology of Education, 19(4), 445-475.

Myers, K., \& de Broucker, P. (2006). Too many left behind: Canada's adult education and training system. Ottawa, ON: Canadian Policy Research Networks.

Quinn, J. (2004). Understanding working-class "drop-out" from higher education through a sociocultural lens: Cultural narratives and local contexts. International Studies in Sociology of Education, 14, 57-74. 
Rokeach, M. (1973). The nature of human values. New York, NY: Free Press.

Shockley-Zalabek, P. (1988). Fundamentals of organizational communication: Knowledge, sensitivity, skills, values. New York, NY: Longman.

Statistics Canada. (2008). Participation, graduation and dropout rates. Retrieved from http://www.statcan.gc.ca/pub/81-595-m/2008070/6000003-eng.htm

Statistics Canada. (2011). Population, urban and rural, by province and territory. Retrieved from http://www.statcan.gc.ca/tables-tableaux/sum-som/lo1/csto1/demo62aeng.htm

\section{Contact Information}

R. J. Purc-Stephenson, Department of Social Sciences University of Alberta Augustana Campus purcstep@ualberta.ca

Rebecca Purc-Stephenson is an Associate Professor of Psychology in the department of Social Sciences in the Augustana Faculty at the University of Alberta. Her research interests include health, illness, work, and access to services for the socially disadvantaged, and her studies use a combination of qualitative and quantitative research methodologies to develop practical/applied theories.

Laura Friesen is a Master's of Education student in Counselling Psychology in the Department of Educational Psychology at the University of Alberta. Her thesis research focuses on experiences of rurality and perceptions of mental wellness in rural and isolated northern communities in Canada. 